\title{
Ethos: a dominação masculina na formação do sujeito
}

\begin{abstract}
Resumo
Encontramos, desde a civilização grega, diversas explicações sobre as questões de gênero e sexualidade, mas já não aceitamos mais como fatalidade o que somos e o que pensamos, pois entendemos que, frutos de uma época pós-moderna, temos plenas condições para nos constituir como sujeitos críticos, capazes de vislumbrar toda a estrutura vigente - estrutura essa fruto de uma cuidadosa arquitetura planejada e executada por instituições que sempre privilegiaram os interesses de apenas algumas classes e, portanto, também de sua visão de mundo. Este artigo se apresenta, pois, como uma possibilidade de reflexão das relações de gênero historicamente constituídas em nossa sociedade; e as pesquisas do sociólogo francês Pierre Bourdieu servirão como base para nos orientar sobre como se constituem as estruturas vigentes e, a partir daí, como podemos vislumbrar uma transformação deste quadro conjuntural, com a consolidação de um modelo crítico de sociedade, cujo resultado permita a emancipação dos sujeitos.
\end{abstract}

Palavras-chave: Gênero; Sexo; Diversidade; Dominação masculina; Emancipação.

\author{
Lauro Roberto Lostada \\ Doutorando em Educação na \\ Universidade Federal de Santa \\ Catarina - UFSC. Assistente \\ Técnico Pedagógico na Escola de \\ Educação Básica Irmã Maria \\ Teresa - Palhoça/SC. \\ Brasil \\ lostada25@yahoo.com.br
}

\section{Para citar este artigo:}

LOSTADA, Lauro Roberto. Ethos: a dominação masculina na formação do sujeito. Revista PerCursos, Florianópolis, v. 17, n.33, p. 144 -161, jan./abr. 2016.

\section{DOI: 10.5965/1984724617332016144}

http://dx.doi.org/10.5965/1984724617332016144 


\title{
Ethos: the male domination in the formation of the subject
}

\begin{abstract}
We found, since the greek civilization, various explanations about the issues of gender and sexuality, but no longer accept more as fatality what we are and what we think, because we believe that the fruits of a post-modern age, we have full conditions for us to be as critical subjects, able to glimpse of all the existing structure - structure this result of careful architecture planned and executed by institutions that always prioritised the interests of only some classes and therefore also of their vision of the world. This article presents itself, because as a possibility of reflection of gender relations historically constituted in our society; and the research of the French sociologist Pierre Bourdieu will serve as a basis to guide us as if they constitute existing structures and, from there, as we can glimpse a transformation of this table cyclical, with the consolidation of a critical model of society, whose result permits the emancipation of the subjects.
\end{abstract}

Keywords: Gender; Sex; Diversity; Masculine domination; Emancipation. 


\section{Introdução}

Sob o ponto de vista dos direitos sexuais, foi elaborada em 1999, durante o XV Congresso Mundial de Sexologia, na China, a Declaração dos Direitos Sexuais como Direitos Humanos Universais, que, em contraposição às abordagens biológica-higienista, moraltradicionalista, terapêutica, religiosa-radical e dos direitos humanos, concebe uma nova maneira de olhar a diversidade (FURLANI, 2008). Essa construção se apresenta como uma resposta direta aos intensos debates sobre a exclusão social feminina promovidos, principalmente, a partir dos anos 1970 e possibilita um debate que culmina na consolidação de novas abordagens sobre o tema, como a dos direitos sexuais, emancipatória e a queer (FURLANI, 2008), que, aos poucos, permitem pensar a ambiguidade, a multiplicidade e a fluidez das identidades sexuais e de gênero, sugerindo, ao mesmo tempo, novas maneiras de pensar a cultura, o conhecimento, o poder e a educação de uma forma geral. Esse processo de consolidação da sexualidade enquanto uma construção social se resume na seguinte passagem da Declaração dos Direitos Sexuais como Direitos Humanos Universais:

A sexualidade é uma parte integral da personalidade de todo ser humano. Seu desenvolvimento pleno depende da satisfação de necessidades humanas básicas como desejo de contato, intimidade, expressão emocional, prazer, ternura e amor. A sexualidade é construída através da interação entre $o$ indivíduo e as estruturas sociais. $O$ desenvolvimento pleno da sexualidade é essencial para o bem-estar individual, interpessoal e social. Os direitos sexuais são direitos humanos universais baseados em liberdade, dignidade e igualdade entre os seres humanos dado que a saúde é um direito humano fundamental, a saúde sexual deve ser um direito humano básico. (...) A saúde sexual é o resultado de um ambiente que reconheça, respeite e exerça estes direitos sexuais (...). (WORLD ASSOCIATION FOR SEXUAL HEALTH, 1999, p.1)

Diante de tais debates, não há como negar que precisamos garantir o respeito aos direitos sexuais das pessoas e à diversidade, mas também não podemos deixar de lembrar que esses direitos, tal como a afirmação do texto acima citado nos faz pensar, são fruto de uma realidade social maior, mais ampla, que confere às pessoas um caráter 
que o caracterizará por toda a vida, engendrando uma marca profunda, frequentemente encarnada, que pode ser traduzida nas palavras da escritora Virgínia Woolf (1977 apud BORDIEU, 2002, p. 112):

Inevitavelmente, nós consideramos a sociedade um lugar de conspiração, que engole o irmão que muitas de nós temos razões de respeitar na vida privada, e impõe em seu lugar um macho monstruoso, de voz tonitruante, de pulso rude, que, de forma pueril, inscreve no chão signos em giz, místicas linhas de demarcação, entre as quais os seres humanos ficam fixados, rígidos, separados, artificiais. Lugares em que, ornado de ouro e de púrpura, enfeitado de plumas como um selvagem, ele realiza seus ritos místicos e usufrui dos prazeres suspeitos do poder e da dominação, enquanto nós, 'suas' mulheres, nos vemos fechadas na casa da família, sem que nos seja dado participar de nenhuma das numerosas sociedades de que se compõe a sociedade.

$\mathrm{Na}$ busca por respostas sobre como o arbitrário se constitui natural em nossa sociedade, construindo homens e mulheres que, inconscientes de seus atos, confirmam as estruturas vigentes e, portanto, reafirmam os processos de dominação e reprodução sociais, utilizaremos como norte o pensamento do sociólogo francês Pierre Bourdieu que, atento às manifestações de sua época, buscou compreender esse dilema, na desconstrução da realidade em que vivia - o que deve ser útil para que possamos também nós desconstruir nossa realidade em busca dos esquemas instituídos em vista da consolidação das relações de poder presentes em nossa sociedade.

Segundo pensadores como Edgar Morin, Martin-Barbero e Henry Jenkins, por exemplo, nós estamos vivendo a era do global, em que as individualidades se convergem em direção ao todo e, portanto, as preferências individuais são postas como pouco significativas diante do papel coletivo que passamos a exercer. Os espaços geográficos entre os sexos passam a ser questionados e as fronteiras rompidas, pois se transformam em lugares de osmose profunda (MARTIN-BARBERO, 1995), em que cada um é solicitado a repensar seus próprios pontos de vista e cultivar um novo olhar diante do diferente. Sob esta perspectiva, este trabalho tem como intenção traçar um itinerário que tangencie o universo em que vivemos e que seja uma ferramenta de reflexão sobre os direitos 
sexuais, na construção de um quadro pós-moderno ${ }^{1}$ de aceitação do diferente - no cenário atual, as pessoas dependem cada vez mais umas das outras, numa complexa relação exo/autopoiética.

Parafraseando Nietzsche (2003): na luta de poder os opostos se transfiguraram em símiles, a ponto de que algumas perspectivas e interpretações se tornam verdade em detrimento de outras que são tidas como visões periféricas e errôneas da realidade. Isso é o que configura o poder nas sociedades e nisto é que consiste a fatalidade do poder da razão.

Está na hora de o homem determinar seu objetivo. Está na hora de o homem plantar o germe de sua mais alta esperança. (...) Mortos estão todos os Deuses; agora, queremos que o super-homem viva. (...) O que há de grandioso no homem é o fato de ele ser uma transição e uma destruição. (NIETZSCHE, 2007, p. 105-106)

Não há razão para que o homem deseje melhorar a humanidade, pois, de alguma forma, ela não existe. O homem precisa melhorar a si mesmo, distanciando-se da massa, enobrecendo-se, “eugenizando-se”" Não se pode, contudo, esperar melhorar o mundo, pois é preciso aprender a viver o mundo no fluxo que a vida exige, com o espírito livre de quem subjuga as convicções e os preconceitos, ensaiando o pensamento pela experiência - na dança; afinal, o mundo é um caos e urge enxergar as possibilidades para o novo, para que possamos criar e ter motivos para bem viver, reconhecendo a fragilidade do real e os múltiplos pontos de vista que fazem com que possamos entender melhor as circunstâncias da existência.

\footnotetext{
${ }^{1}$ De maneira geral, a modernidade era caracterizada pela crença irrefutável na ciência, na razão e no progresso como guias da humanidade. Estes princípios, contudo, deixaram de ser referências a partir do momento em que a realidade mostrou um resultado decepcionante. O ideal da modernidade havia fracassado e, deste modo, se inicia uma nova era: a pós-modernidade. A pós-modernidade é basicamente uma crítica da modernidade, de seus valores e princípios.

${ }^{2} \mathrm{O}$ conceito de eugenia foi historicamente retorcido por interesses específicos e utilizado para justificar as concepções do nazismo, sem, contudo, ser a expressão mesma do pensamento nietzscheniano, o qual se opunha veemente a tais pressupostos. Para Nietzsche, o "super-homem" era um ideal de indivíduo superior, que se elevava acima da mediocridade, como fruto do esforço e da educação e não da seleção natural.
} 
A partir de tais pressupostos, abre-se a possibilidade de uma crítica sociológica que sirva para desvelar o real, promovendo um debate sobre o que pode ser feito para mudar essa situação e democratizar efetivamente a sociedade. É preciso promover uma crítica da educação que recebemos, de nossas raízes culturais, e definir a função de tais canais como suportes para uma sociedade atenta aos ditames da dominação e da reprodução social, como ferramenta de conscientização e de libertação. Oferecer sentido às coisas é hoje uma necessidade, pois só assim as pessoas poderão lutar por seus interesses e aspirações. A dominação, profundamente enraizada nas estruturas e nos corpos, se constitui como uma constância trans-histórica que gera esquemas inconscientes, e, portanto, ela somente pode ser superada lentamente, com muito trabalho e persistência.

Este trabalho objetiva apresentar de forma geral, talvez até um tanto superficial (há que se considerar a dimensão do trabalho elaborado pelo autor escolhido para esta análise), os traços que consolidaram nosso modelo patriarcal e androcêntrico de sociedade, como forma de colaborar para um debate emancipatório que, de algum modo, possa nutrir ações que colaborem para a transformação de nosso modo de ser, de pensar e de agir, que, por tanto tempo, infelizmente, tem menosprezado as mulheres.

\section{A identidade de gênero como construção social}

A identidade de gênero e o preconceito decorrente de sua afirmação na vida das pessoas, com relação ao diferente, são problemas que têm gerado inúmeras pesquisas que procuram desconstruir esse paradoxo em busca do ponto a partir do qual tudo pode ser mudado. A pós-modernidade, em sua essência revolucionária, reestrutura a tessitura social, determinando novas perspectivas diante do homem, do mundo e de suas relações. Assim, Pierre Bourdieu, pensador francês do último século, na expectativa de entender um pouco a constituição do nosso modo de ser (éthos ${ }^{3}$ ), teceu uma "genealogia da

\footnotetext{
${ }^{3}$ Segundo o dicionário Novo Aurélio éthos é: Modo de ser, temperamento ou disposição interior, de natureza emocional ou moral. O espírito que anima uma coletividade, instituição, etc. Aquilo que é característico e predominante nas atitudes e sentimentos dos indivíduos de um povo, grupo ou comunidade, e que marca suas realizações ou manifestações culturais.
} 
moral" que pode ser encontrada em sua completude no livro "A dominação masculina". Neste trabalho, tentaremos resgatar apenas alguns traços da sua obra como auxílio para nossas reflexões. Assim, já no início da obra do autor, encontramos um relato do desconforto do mesmo diante da ordem estabelecida, com suas relações de dominação, privilégios e injustiças, tidas como naturais, principalmente no que diz respeito à violência simbólica exercida pelos homens. O autor coloca como meta a reimposição do caráter paradoxal à doxa (opinião), bem como a manifestação dos processos rituais que levam o arbitrário a assumir um caráter natural, objetivando que possamos nos conscientizar, através de uma análise materialista da economia e de uma etnologia, da situação paradoxal em que nos encontramos e reconstruir as diferenças entre o masculino e o feminino, o heterossexual e homossexual, tal como se apresentam, sem o desvio socialmente determinado pela família, pela escola, pela igreja ou/e pelo estado instituições que representam, segundo o autor, a formação/conformação dos sujeitos.

Incluídos no objeto que buscamos entender, para Bourdieu, incorporamos esquemas inconscientes de percepção e apreciação masculinas; e, por isso, precisamos encontrar uma estratégia eficiente para objetivar o sujeito da "objetivação científica". Essa estratégia consiste em transformar o exercício da reflexão transcendental, visando explorar as categorias do entendimento ou as formas de classificação, conforme dizia Durkheim, como instrumento de análise do inconsciente androcêntrico capaz de operar a objetivação das categorias deste inconsciente. Sob este ponto de vista verificamos, por exemplo, a construção social dos corpos, que nada mais é do que a naturalização de esquemas de pensamento marcados como sistemas de classificação e diferenciação no curso do mundo, de maneira que funcionam como esquemas de percepção, pensamento e ação, configurados como habitus ${ }^{4}$ dos agentes.

A socioanálise permite que se ultrapasse a atitude natural ou a experiência dóxica, de que falava Bertrand Russell, para se perceber as estruturas mais profundas que legitimam as configurações sociais de dominação masculina, evidentes por sua

\footnotetext{
${ }^{4}$ Para Bourdieu, habitus são as disposições duráveis e transmissíveis em relação à posição do indivíduo no campo (local de atuação social do indivíduo dentro da sociedade).
} 
naturalidade legitimada: “o mundo constrói o corpo como realidade sexuada e como depositário de princípios de visão e de divisão sexualizantes” (BOURDIEU, 2002, p. 18).

Segundo a abordagem biológica-higienista e moral-tradicionalista, as diferenças de sexo e as diferenças anatômicas entre os sexos servem comumente como justificativa natural da diferença constituída, gerando, por sua vez, a divisão do trabalho e a organização cognitiva da sociedade em segmentos. Consideremos que essa divisão se estabelece à custa de escolhas orientadas, que acentuam certas diferenças e obscurecem semelhanças entre os sexos, de modo que podemos encontrar todo um sentido social sobre a postura da mulher e as profissões que elas podem ou não exercer. Da mesma maneira, o homem estabelece também no ato sexual uma relação de dominação, de apropriação consentida, já que vê na situação uma oportunidade de afirmar sua dominação através do gozo e do prazer, tanto sentido quanto promovido, em detrimento aos desejos e expectativas frustradas da mulher.

Se o ato sexual é uma relação de dominação é porque está fundado num princípio de divisão entre o desejo masculino de possuir e dominar e no reconhecimento feminino de subordinação e dominação - amor fati. Da mesma forma esse desejo de dominação também se exerce nas relações homossexuais, ao ponto de transparecer uma relação clara entre "penetração e poder", em que um dos envolvidos é feminizado e, portanto, desprovido de seu estatuto de honra e dignidade masculina.

É importante lembrar, contudo, sobre a definição de corpo, e especialmente dos órgãos sexuais, que não é o falo ou a falta dele que fundamenta essa visão de mundo, mas sim esta visão de mundo organizada sobre a divisão de gêneros como essências sociais hierarquizadas é que organiza e fundamenta essa relação de subordinação (BOURDIEU, 2002, p. 32-33). Assim sendo, essa perspectiva legitima uma relação de dominação, inscrevendo-a em uma natureza biológica, ora naturalizada.

O masculino e o feminino são, dessa maneira, resultado de um trabalho coletivo de socialização difusa e contínua para a formação de identidades e, portanto, de um habitus diferenciado segundo uma divisão sexista ${ }^{5}$. Nesse contexto social de incorporação de um

\footnotetext{
${ }^{5}$ Para Bourdieu, essa relação é descrita como "bildung", que significa a incorporação do habitus relativo ao
} 
habitus ligado ao gênero é que encontramos em Bourdieu o conceito de ritos de instituição, que são operações de diferenciação que visam destacar em homens e em mulheres os signos específicos de sua distinção sexual, estimulando as práticas convenientes, ao passo que desencorajam ou proíbem as práticas impróprias no que diz respeito também ao ato de se vestir, na forma de andar e se portar, no falar, como se a feminilidade se medisse pela arte de se fazer pequena (héxis corporal). Neste sentido, é interessante a colocação de Bourdieu de que, embora pareça haver uma libertação feminina em nossa época, expressa, principalmente, através da exibição do corpo, essa liberação continua subordinada à visão dominante masculina, que continua a determinar e a delimitar as posturas permitidas ou proibidas, como também as virtudes e os valores negativos que possuem. De toda sorte, submetidas à resignação e à discrição, incapazes de subverter a ordem estabelecida, as mulheres acabam desenvolvendo estratégias de resistência que, de modo geral, não rompem com a situação, servindo apenas como confirmação da visão dominante, mesmo que inconsciente, de que as mulheres são maléficas e, portanto, devem ser "vigiadas e punidas/dominadas".

A dominação masculina encontra reunidas as condições necessárias para a sua existência e esta primazia se confirma na objetividade das estruturas sociais e de atividades produtivas/reprodutivas baseadas na divisão sexual do trabalho que reserva para o homem sempre a melhor parte (BOURDIEU, 2002, p. 45). Quanto às mulheres, elas aplicam a essa realidade percebível esquemas de pensamento que são frutos da incorporação dessas relações de poder como fundamentos da ordem simbólica, constituindo, portanto, suas ações como atos de reconhecimento dóxico da violência simbólica a que estão submetidas como resultado de um trabalho incessante de estruturas de reprodução (família, igreja, escola, estado, etc.).

Sobre a possibilidade de conscientização da violência sofrida, Bourdieu ressalta que a violência simbólica se consolida através da adesão que o dominado não pode deixar de oferecer ao dominante, quando ele não dispõe de instrumentos de conhecimento incorporados para pensá-la em sua relação com a dominação. O dominado, sendo 
constituído como tal, não desenvolve outras ferramentas a não ser as que lhe foram oferecidas pelo "jogo" em que se encontra, de sorte que ele não pode enxergar a sua situação senão com as lentes que lhe foram forjadas, confirmando, pois, as estruturas sociais em sua distinção.

A lógica da dominação simbólica, diante das argumentações apresentadas, não se situa apenas na relação entre a pressão e o consentimento, mas se constitui também e principalmente através de esquemas de percepção, de avaliação e de ação que fazem parte de um habitus. Esses esquemas configuram uma relação de conhecimento obscura a ela mesma, e com efeitos duradouros na sociedade (magia), refletida nas decisões subjetivas da consciência e dos controles da vontade (BOURDIEU, 2002, p. 49-50).

A força simbólica destes mecanismos é um poder que se exerce sobre os corpos, como que por magia, sem qualquer coação física, através de predisposições colocadas sob a forma de emoções corporais (vergonha, humilhação, timidez, ansiedade, culpa) ou paixões e sentimentos (amor, admiração, respeito). A violência simbólica não pode ser vencida apenas com as armas da consciência e da vontade porque os efeitos e as condições de sua eficácia estão gravados no mais íntimo dos corpos sob a forma de predisposições, de modo que podemos concluir que o poder simbólico não pode existir sem a colaboração dos dominados, que se subordinam a ele porque o constroem como poder (coação/consentimento).

De certa maneira, somente se pode romper com a relação de cumplicidade entre dominados e dominantes quando for promovida uma transformação das condições que levam os dominados a adotar, sobre si mesmos e sobre os dominantes, o próprio ponto de vista dos dominantes (BOURDIEU, 2002, p. 54).

Na lógica da dominação vigente, as mulheres são vistas como objetos ou símbolos cujo sentido se constitui fora delas e cuja função seria perpetuar ou aumentar o capital simbólico masculino, de modo que se estabelece até mesmo uma economia de trocas simbólicas, em que as mulheres circulam como signos fiduciários e como elementos de instituição de relações entre os homens, sendo, portanto, reduzidas a instrumentos de produção e reprodução do capital simbólico e social. Há, na nossa cultura, uma 
hipervalorização da primazia masculina em relação ao mundo feminino, de sorte que até mesmo a fecundação, por exemplo, é apreciada em detrimento de toda a gestação, do parto e da amamentação realizada pela mulher - vide a importância adotada ao conceito de fecundar nos estudos da biologia. A divisão sexual se estabelece paralelamente na divisão das atividades produtivas, bem como também na divisão do trabalho de manutenção do capital social e do capital simbólico que assegura aos homens a primazia em todas as atividades oficiais, construindo uma illusio masculina, que cria o princípio indiscutido de todos os deveres do homem para consigo mesmo (dever ser). Assim, para a promoção do "dever ser" se estabelecem estratégias de toda ordem (de fecundidade, matrimoniais, educativas, econômicas, de sucessão, etc.) para a transmissão dos poderes e dos privilégios herdados, ou seja, para a manutenção da honra ou, o que daria no mesmo, do capital simbólico possuído em comum por uma linhagem ou família.

É importante deixar claro, contudo, que a dominação masculina não é um fator exclusivamente positivo para os dominantes, como é de se pensar eventualmente. Bourdieu alerta para o fato de que o amor fati (amor do destino), como inclinação corporal a realizar uma identidade constituída em essência social e assim transformada em destino, produto de um trabalho social de nominação e inculcação, é uma cilada para o homem que se vê diante de uma permanente tensão e contensão para dar provas de sua virilidade e de sua coragem, mesmo essa sendo uma paradoxal demonstração do medo de se apresentar fraco diante dos demais.

Para desvelar a dominação masculina é preciso detectar e compreender as manifestações próprias do nosso inconsciente, que se entrega e se trai em relances. Assim, a sociedade estabelece o que há por ser feito ou o que não pode ser feito, segundo determinada categoria. A lógica social do que chamamos, portanto, vocação, tem por efeito produzir o encontro harmonioso entre as disposições e as posições, de modo que as vítimas da dominação aceitem sua "vocação" com felicidade, exercendo papéis subordinados ou subalternos. A vocação é, pois, um apelo à ordem estabelecida pelo habitus (herança). E, sobre este ponto, pode-se entender que a masculinidade é uma espécie de nobreza, pois o homem não pode rebaixar-se a realizar certas tarefas, que, realizadas por eles, se tornam objeto de nobreza, enquanto que, por outro lado, 
realizadas por mulheres, passam por insignificantes e imperceptíveis na estrutura social e doméstica. Essa divisão sensível, do particular das famílias à esfera do trabalho, age de maneira a ajustar as esperanças às oportunidades, as aspirações às possibilidades, gerando disposições permanentes que desencorajam as mulheres a realizar o que não é esperado delas (incorporação de um habitus). Sobre essa relação, é interessante a leitura de um trecho de Jan Morris, (1974 apud BOURDIEU, 2002, p. 77) transexual que mudou seu corpo de homem para mulher, descrevendo sua experiência de transição:

Quanto mais eu era tratada como mulher, mais eu me tornava mulher. Eu me adaptava, com maior ou menor boa vontade. Se acreditavam que eu era incapaz de dar macha à ré, ou de abrir garrafas, eu sentia, estranhamente, que me tornava incompetente para tal. Se achavam que uma mala era muito pesada para mim, inexplicavelmente, eu também achava que sim.

A definição dominante da prática é carregada de implicações sexuadas, que definem, por exemplo, a excelência como uma particularidade masculina. Assim, para que as mulheres possam ocupar cargos de autoridade nesse tipo de sociedade elas precisam desenvolver atributos que são naturais na formação dos homens. Essa diferença, aliás, só surge quando acaba produzindo sobre o dominado o ponto de vista do dominante numa relação histórica criada através da gênese de um habitus feminino fundamentalmente orientado pelo feedback social (pais e pares, etc.), de modo que o corpo percebido é determinado socialmente tanto pelas condições de sua produção (héxis corporal) quanto pelos esquemas de percepção (o poder simbólico depende da posição relativa daquele que percebe e daquele que é percebido).

Toda essa estrutura impõe, por certo, suas pressões aos dois termos da relação de dominação, fazendo com que mesmo para os dominantes sejam engendradas terríveis exigências, como no caso do pai que, por deter o monopólio da violência simbólica legítima, precisa exercer a ação psicossomática que conduz à somatização da lei. A palavra paterna se configura, por exemplo, como uma profética predição, que, por sua força, conduz a probabilidade em fatalidade, expressando o mundo no que ele tem de 
mais impiedoso, livre da indulgência feminina e da cegueira materna (BORDIEU, 2002, p. 42-49).

Ademais, para se manter a estrutura em funcionamento, a illusio ${ }^{6}$ age no sentido de fazer crer que o jogo merece ser jogado até o fim, segundo as regras impostas, através da objetivação de uma libido dominandi (desejo de dominar). A dominação masculina encontra suporte no desconhecimento que favorece, ao dominante, a aplicação de categorias de pensamento constituídas na própria relação de dominação e que pode levar a esta forma limite do amor fati (amor do dominante e de sua dominação), que implica renúncia a exercer a libido dominandi (desejo de dominar).

É espantosa a constatação da autonomia das estruturas sexuais em relação às estruturas econômicas, dos modos de reprodução em relação aos modos de produção, de forma que Bourdieu se questiona sobre as mudanças que acontecem na história e de como, mesmo diante de tais reordenações, a estrutura de dominação masculina permanece, de maneira geral, inalterada. Para responder este problema, o autor começa dizendo que "o eterno na história não pode ser senão o produto de um trabalho histórico de eternização" (BOURDIEU, 2002, p. 100); e, portanto, para compreender a eternização da dominação masculina, é preciso reconstruir a história do trabalho histórico de deshistorização, ou seja, a história da criação/recriação das estruturas da dominação masculina, principalmente através de instituições como a igreja, o estado e a escola, por exemplo.

Deste modo, a pesquisa histórica, assim constituída, não pode se contentar com a descrição das formações das condições masculina e feminina, devendo empenhar-se em estabelecer o sistema de agentes e das instituições que contribuíram para a história das relações de sexo, suas combinações, estratégias e mecanismos estruturais. Ao pensar as invariantes trans-históricas da relação entre os sexos, a história se obriga a tomar como objeto o trabalho histórico de des-historização que as produziu e reproduziu continuamente, isto é, o trabalho constante de diferenciação a que os homens e mulheres estão submetidos e que os leva a agir de tal ou qual modo específico; bem

\footnotetext{
${ }^{6}$ A illusio se constitui como o conjunto das estratégias incorporadas no indivíduo que o fazem crer que o jogo é importante e que, portanto, precisa ser jogado.
} 
como deveria se obrigar a descrever e analisar também a construção/reconstrução social dos princípios de visão e divisão dos sexos.

A reprodução das estruturas de dominação masculina, até os dias de hoje, esteve quase sempre garantida através da ação da família, da igreja, e da escola, que agiam em comum sobre as estruturas inconscientes. À família coube historicamente o principal papel na reprodução da dominação e da visão masculinas, através de sua precocidade, direito e linguagem na vida das pessoas. Quanto à igreja, ela sempre desenvolveu ritos e iconografias voltadas à reprodução de um ideário de dominação masculina em detrimento ao que é específico do universo feminino. Já a escola, por sua vez, como um terceiro grande elemento da reprodução, age no sentido de transmitir os pressupostos da representação patriarcal através de suas práticas e divisões em relação a cursos e disciplinas apropriados para certos grupos e inapropriados para outros, por exemplo. Nessa onda de instituições reprodutoras da estrutura de dominação masculina (estruturas estruturantes) se inscreve também o Estado, que ratifica e reforça as determinações geradas nesse universo patriarcal privado, instituindo-o como um universo reconhecido publicamente e auferido como regra da ordem social e, por extensão, como regra moral. Por último, poderíamos incluir a esse grupo de instituições estruturantes a própria mídia, que hoje exerce extraordinário poder sobre a vida das pessoas, persuadindo-as insistentemente sobre os hábitos e posturas adequados/inadequados.

Atualmente, contudo, devido aos movimentos feministas das últimas décadas, bem como aos diversos fatores que se aplicam ao universo feminino, como o acesso è educação e ao trabalho, o distanciamento das tarefas domésticas, entre outros, a dominação masculina não se impõe mais como evidência indiscutível. Aliás, nesse sentido, o grande motor dessa mudança é a escola, pois através de uma abertura maior às mulheres ela promoveu, correlativamente, uma independência econômica e uma transformação das estruturas familiares.

Assim, apesar da inércia do habitus e do direito, que estruturam um modelo de família e de sexualidade legítima, esse novo modelo de educação e, por extensão, de trabalho, aberto às mulheres, tem contribuído para desmobilizar essa dóxa e ampliar os espaços de possibilidades em matéria de sexualidade, o que não significa que as mulheres 
já consigam alcançar os cargos e as carreiras mais elevadas das estruturas, ainda reservadas tradicionalmente para os homens em suas especificidades constitutivas.

A estrutura se perpetua nos pares de oposição homólogos às grandes divisões tradicionais e o acesso das mulheres aos cargos e carreiras mais elevados se dá, normalmente, por sua desvalorização ou pela deserção à ordem estabelecida, bem como suas oportunidades de acesso decrescem à medida que atingem posições mais raras e elevadas. Assim, a estrutura constituída dissimula uma situação irreal de igualdade de oportunidades às mulheres, que se vêem obrigadas a "masculinizar-se" diante do fato de estarem separadas dos homens por um coeficiente simbólico negativo.

Se as estruturas antigas parecem então continuar exercendo força sobre as novas gerações é porque agem ainda sobre três grandes princípios gerais: 1. As funções que convêm às mulheres se situam como prolongamento das funções domésticas; 2 . A mulher não pode ter autoridade sobre os homens; 3. O homem tem o monopólio sobre a manutenção dos objetos técnicos e das máquinas (BOURDIEU, 2002, p. 111-114).

A permanência das estruturas antigas se constrói principalmente porque o habitus se apresenta como uma série de princípios transmitidos essencialmente corpo a corpo; inculcados, aquém da consciência e do discurso, escapando, portanto, às tomadas de controle consciente e às transformações ou correções promovidas. Sendo, assim, uma construção inconsciente, corporificada, as estruturas herdadas e transmitidas se apresentam como um grande desafio da pós-modernidade - há que se desenvolver maneiras de emancipar os sujeitos, promovendo uma transformação da realidade então consolidada. O paradigma crítico, por exemplo, aponta o agir comunicativo como base desse processo em que, através do diálogo, se pode organizar um movimento de emancipação e, por extensão, uma mudança dos ditames então constituídos e institucionalizados.

O mundo social funciona, contudo, como um mercado de bens simbólicos dominado pela visão masculina e a posição das mulheres no mercado de bens simbólicos explica o que há de mais essencial nas disposições femininas (as roupas e seu caráter de sedução, por exemplo). Essas disposições femininas fundamentam a posição das 
mulheres na família e nas empresas, onde elas devem exercer um papel de gestão do capital simbólico, como instrumentos de exibição ou de manipulação simbólicos. Assim sendo, a reprodução da dominação masculina se dá através da permanência dos bens simbólicos (entre eles o casamento, os laços familiares e a herança) e sua relativa autonomia, que é concebida e reforçada pelas instituições de reprodução como a família, a escola, a igreja e a mídia.

A dominação, profundamente enraizada nas estruturas e corpos, se constitui como uma constância trans-histórica que gera esquemas inconscientes, e, portanto, não pode ser abolida com um simples ato de magia performática, como parece acontecer, por exemplo, nas amizades e no amor, que transparecem uma trégua em que a dominação parece dominada; processo que, na verdade, se realiza lentamente, com esforço e dedicação, na efetivação de um novo cenário em que a garantia dos direitos seja respeitada e o sujeito seja, ele mesmo, responsável por sua história.

\section{A possibilidade da mudança através da práxis política}

As considerações levantadas até o momento permitem dizer que a sociedade se constituiu num modelo arbitrário de civilização, que tem uma identidade modelada em torno de princípios arcaicos e androgênicos que excluem a diversidade, gerando toda uma trama de mecanismos de opressão e de segregação para manter as relações sociais, trabalhistas e culturais como historicamente foram constituídas (BOURDIEU, 1998).

Pudemos perceber que talvez somente a ação política comprometida, que leve em conta os efeitos da dominação que se exercem através da cumplicidade objetiva entre as estruturas incorporadas e as estruturas das instituições em que se realizam e se produzem/reproduzem a ordem masculina e a ordem social (estado, escola, igreja, mídia, família), poderá, a longo prazo, trabalhando com as contradições inerentes aos diferentes mecanismos ou instituições referidas, contribuir para o desaparecimento progressivo da dominação masculina e, portanto, para a construção de uma sociedade igualitária e justa.

Nessa tessitura, a família, os meios de comunicação, as escolas e outras instituições sociais têm, portanto, um papel determinante no comportamento dos jovens 
e, por extensão, como as relações de gênero se constituem. A família, mesmo que não dialogue abertamente sobre sexualidade, é quem oferece as primeiras noções sobre o que é adequado ou não, seja através de gestos, de expressões, recomendações ou mesmo através das proibições. Os meios de comunicação, em sua programação corriqueira, veiculando cenas ou determinados comentários/brincadeiras, frequentemente reforçam preconceitos. Quanto à escola, ela muitas vezes deixa de oferecer um espaço dialógico e reflexivo, restringindo-se aos conteúdos estanques de seus currículos fechados.

As considerações que fizemos neste trabalho nos fazem ter a certeza de que sem a participação consciente destes mecanismos estruturais/estruturantes não haverá uma mudança efetiva na sociedade e tampouco nas pessoas, de modo que se torna necessário reformar o pensamento, na construção de um novo cenário em que o diferente possa ser aceito e cultivado. A contradição que se institui é a de que o mesmo mecanismo que forja a desigualdade é aquele que tem a possibilidade e o dever de gerir a igualdade. Essa mudança das estruturas seria diretamente responsável pela construção de uma realidade emancipatória, na qual os sujeitos construiriam a sua própria história, com liberdade e igualdade. Assim, segundo as abordagens crítico-sociais aqui expostas, o que impulsiona esse projeto emancipatório é o diálogo, cujo papel potencializa uma ação transformadora e, portanto, um novo paradigma social.

\section{Referências}

BOURDIEU, Pierre. A dominação masculina. Tradução Maria Helena Kühner. 3. ed. Rio de Janeiro: Bertrand Brasil, 2002.

BOURDIEU, Pierre. As contradições da herança. In: NOGUEIRA, M.A.; CATANI, A. Escritos de educação. Petrópolis: Vozes, 1998.

FURLANI, Jimena. Abordagens contemporâneas para educação sexual. In: FURLANI, Jimena (Org.). Educação sexual na escola: equidade de gênero, livre orientação sexual e igualdade étnico-racial numa proposta de respeito às diferenças. Florianópolis: UDESC, 2008. 
MARTÍN-BARBERO, Jesús. América Latina e os anos recentes: o estudo da recepção em comunicação social. In: SOUSA, Mauro Wilton de (Org), et al.. Sujeito, o lado oculto do receptor. São Paulo: Brasiliense, 1995.

MORRIS, J. Conundrum, New York, Harcourt, Brace, Jovanovich, 1974. In: BOURDIEU, Pierre. A dominação masculina. Tradução de. Maria Helena Kühner. 3. ed. Rio de Janeiro: Bertrand Brasil, 2002.

NIETZSCHE, Friedrich. Assim falava Zaratustra: um livro para todos e para ninguém. Petrópolis: Vozes, 2007.

NIETZSCHE, Friedrich. Ecce homo: de como a gente se torna o que a gente é. Porto Alegre: L\&PM, 2003.

WOOLF, Virginia. Trois guinées. Paris: Éditions dês femmes, 1977. In: BOURDIEU, Pierre. A dominação masculina. Tradução Maria Helena Kühner. 3. ed. Rio de Janeiro: Bertrand Brasil, 2002.

WORLD ASSOCIATION FOR SEXUAL HEALTH. Declaração dos direitos sexuais como direitos humanos universais. Czech Republic, 1999. Disponível em: <http://www.worldsexology.org/wp-content/uploads/2013/08/DSR-Portugese.pdf>. Acesso em: 03 maio 2015. 